\title{
Mechanisms of the antidiabetic action of subcutaneous glucagon-like peptide-1(7-36)amide in non-insulin dependent diabetes mellitus
}

\author{
J Schirra, P Leicht, P Hildebrand ${ }^{1}$, C Beglinger ${ }^{1}$, R Arnold, \\ B Göke and M Katschinski \\ Clinical Research Unit of Gastrointestinal Endocrinology at the Department of Gastroenterology and Endocrinology, Philipps-University, 35033 Marburg, \\ Germany and ${ }^{1}$ Department of Gastroenterology, Kantonsspital, CH-4031 Basel, Switzerland \\ (Requests for offprints should be addressed to J Schirra)
}

\begin{abstract}
Twelve patients with non-insulin dependent diabetes mellitus (NIDDM) under secondary failure to sulfonylureas were studied to evaluate the effects of subcutaneous glucagon-like peptide-1(7-36)amide (GLP-1) on (a) the gastric emptying pattern of a solid meal $(250 \mathrm{kcal})$ and (b) the glycemic and endocrine responses to this solid meal and an oral glucose tolerance test (OGTT, $300 \mathrm{kcal}$ ). $0.5 \mathrm{nmol} / \mathrm{kg}$ of GLP-1 or placebo were subcutaneously injected $20 \mathrm{~min}$ after meal ingestion. GLP-1 modified the pattern of gastric emptying by prolonging the time to reach maximal emptying velocity (lag period) which was followed by an acceleration in the post-lag period. The maximal emptying velocity and the emptying half-time remained unaltered. With both meals, GLP-1 diminished the postprandial glucose peak, and reduced the glycemic
\end{abstract}

response during the first two postprandial hours by $54 \cdot 5 \%$ (solid meal) and $32 \cdot 7 \%$ (OGTT) $(P<0 \cdot 05)$. GLP-1 markedly stimulated insulin secretion with an effect lasting for $105 \mathrm{~min}$ (solid meal) or $150 \mathrm{~min}$ (OGTT). The postprandial increase of plasma glucagon was abolished by GLP-1. GLP-1 diminished the postprandial release of pancreatic polypeptide. The initial and transient delay of gastric emptying, the enhancement of postprandial insulin release, and the inhibition of postprandial glucagon release were independent determinants $(P<0 \cdot 002)$ of the postprandial glucose response after subcutaneous GLP-1. An inhibition of efferent vagal activity may contribute to the inhibitory effect of GLP-1 on gastric emptying.

Journal of Endocrinology (1998) 156, 177-186

\section{Introduction}

Glucagon-like peptide-1(7-36)amide (GLP-1) is an incretin hormone of the entero-insular axis. Derived by posttranslational processing of the precursor preproglucagon in L-cells of the intestinal mucosa, it is promptly released in response to meal ingestion (Göke et al. 1991, Fehmann et al. 1995a, Schirra et al. 1996a). It has a strong insulinotropic action mediated via a specific receptor on the pancreatic B cell (Kreymann et al. 1987, Fehmann et al. 1992, Thorens et al. 1993, Kolligs et al. 1995, Wang et al. 1995). Intravenous infusions of GLP-1 decrease postprandial glycemia by enhancing insulin secretion, lowering glucagon release, and stimulating insulin-independent glucose disposal in peripheral tissues (Kreymann et al. 1987, Gutniak et al. 1992, D’Alessio et al. 1994, 1995). These effects are preserved in patients with non-insulin dependent diabetes mellitus (NIDDM, Gutniak et al. 1992, Nathan et al. 1992, Nauck et al. 1993). Therapy with sulfonylureas and/or insulin is afflicted with the risk of hypoglycemia and possibly accelerated atherosclerosis due to hyperinsulinemia (Robertson et al. 1988). In contrast, the insulinotropic action of GLP-1 is glucosedependent (Kreymann et al. 1987, Weir et al. 1989). Moreover, it has recently been shown that infusion of GLP-1 in NIDDM improved the impaired basal and stimulated glucose-responsiveness of the compromised pancreatic B-cell (Rachman et al. 1996, Ahrén et al. 1997). Therefore, GLP-1 represents a promising new concept in the therapy of NIDDM.

In addition to the endocrine effects, intravenous infusions of GLP-1 inhibited gastric emptying of liquid meals (Wettergren et al. 1993). A preprandial subcutaneous injection of GLP-1 in healthy subjects has been shown to dose-dependently delay gastric emptying of a mixed liquid meal by prolonging the lag period, but without affecting the maximal emptying velocity or the total emptying time (Schirra et al. 1997). The initial delay of gastric emptying was characterized as one of the determinants of the reduction in postprandial glycemia. The inhibition of gastric emptying was accompanied by suppression of antro-duodenal motor activity. Therefore, GLP-1 is 
discussed as a hormonal mediator of intestinal feedback inhibition of gastric emptying.

Effects of subcutaneous GLP-1 in NIDDM are only poorly characterized. The significance of GLP-1-induced effects on gastric emptying to the overall antidiabetic action of the peptide needs further evaluation. Therefore, the present study aimed to address the mechanisms of the effects of subcutaneous GLP-1 on the control of postprandial glycemia in NIDDM. Keeping in mind the rapid peptide absorption from subcutaneous tissue (Gutniak et al. 1994, Schirra et al. 1997), we injected the peptide in the early postprandial phase when postprandial glycemia evolves and emptying velocity increases.

\section{Materials and Methods}

\section{Subjects}

The studies were approved by the Ethical Committee of the Medical Faculty of the Philipps-University of Marburg, and all participants provided written informed consent after full explanation of the purpose and nature of all procedures used. Twelve patients (five women, seven men) suffering from NIDDM with a secondary failure to sulfonylureas participated in the studies $(64 \pm 3$ years of age, range 48-75 years). Five of the patients were overweight (body mass index (BMI) $30 \cdot 7 \pm 2 \cdot 4 \mathrm{~kg} / \mathrm{m}^{2}$, range $25 \cdot 1-38.5 \mathrm{~kg} / \mathrm{m}^{2}$ ) and seven were in the normal range of body weight (BMI $22.3 \pm 0.7 \mathrm{~kg} / \mathrm{m}^{2}$, range 19.8 $24 \cdot 8 \mathrm{~kg} / \mathrm{m}^{2}$ ). Before admission, all patients were treated with diet and sulphonylurea derivatives, one patient additionally with acarbose. The patients were admitted to the hospital because of unsatisfactory metabolic control as indicated by $\mathrm{HbA}_{1 \mathrm{c}}$ values of $10 \cdot 2 \pm 0 \cdot 8 \%$ (glycosylated hemoglobin, normal range 4-6\%) to initiate therapy with insulin. Initial diagnosis of diabetes was made $7 \cdot 2 \pm 1 \cdot 6$ years before. After adjustment of the glycemic control with regular insulin for at least 4 days, patients were included in the study. A standard diet $(1221 \pm 74 \mathrm{kcal}$ per day $)$ with restriction of simple carbohydrates was recommended at least 4 days before and during the study. During the study, blood glucose was controlled by subcutaneously injected regular insulin. The last insulin dose was given at $2200 \mathrm{~h}$ on the days before the experiments. None of the patients suffered from gastrointestinal, bronchopulmonary or hepatic disorders, and none had a history of abdominal surgery other than appendectomy. There was one patient with mild retinopathy, three patients presented with diabetic nephropathy (endogenous creatinine clearance $>50 \mathrm{ml} / \mathrm{min}$ ), and seven patients displayed peripheral neuropathy. None of the patients was taking any medication known to interfere with autonomic nerve function or gastric emptying.

\section{Experimental protocol}

All studies were started after an overnight fast at $0730 \mathrm{~h}$ in the morning. Four experiments were performed on each subject in random order on 4 consecutive days. On 2 days, an oral glucose tolerance test with $75 \mathrm{~g}$ glucose (OGTT, $300 \mathrm{ml}$, $300 \mathrm{kcal}$, Boehringer Mannheim, Mannheim, Germany) was given. On the other 2 days, a ${ }^{13} \mathrm{C}$-labeled octanoic acid breath test with a mixed solid-liquid test meal was performed for determination of ${ }^{13} \mathrm{CO}_{2}{ }^{-}$ exhalation as a measure of gastric emptying (Ghoos et al. 1993). The latter test meal consisted of a scrambled egg with the yolk doped with $100 \mathrm{mg}{ }^{13} \mathrm{C}$-octanoic acid. Yolk and egg white were baked separately but administered together with two slices of white bread and $5 \mathrm{~g}$ margarine, followed immediately by $150 \mathrm{ml}$ water. Total caloric content of the meal was $250 \mathrm{kcal}$. The OGTTs were consumed in about $2 \mathrm{~min}$, the ${ }^{13} \mathrm{C}$-octanoic acid test meal in less than $10 \mathrm{~min}$.

With the OGTT and the solid meal, $0.5 \mathrm{nmol} / \mathrm{kg}$ GLP-1(7-36)amide dissolved in 1\% human serum albumin (HSA) or 1\% HSA alone serving as control were subcutaneously injected into the abdominal wall $20 \mathrm{~min}$ after meal intake. In each experiment, blood samples were drawn through an indwelling venous catheter retrogradely placed into a dorsal hand vein. Hand and forearm were continuously warmed throughout the experiment at exactly $40^{\circ} \mathrm{C}$ by an infrared lamp regulated by a sensor controlled biothermostat to arterialize the venous blood (heated hand). Blood samples were taken $10 \mathrm{~min}$ and immediately before meal ingestion as well as $15,30,45$, $60,90,120,150,180,210$ and $240 \mathrm{~min}$ after the end of meal ingestion for determination of the immunoreactivities of GLP-1, insulin, C-peptide, glucagon, and pancreatic polypeptide $(\mathrm{PP})$, the latter reflecting the cholinergic tone. Blood was collected in ice-chilled EDTA tubes containing 1000 kallikrein inhibitory units aprotinin/ml of blood. Blood samples were kept on ice to prevent in vitro degradation of GLP-1(7-36)amide (Deacon et al. 1995a) and centrifuged at $4{ }^{\circ} \mathrm{C}(1000 \mathrm{~g})$ for $10 \mathrm{~min}$. The plasma was stored at $-20^{\circ} \mathrm{C}$ until assayed. Measurements of glucose in arterialized blood were performed at $15 \mathrm{~min}$ intervals until the end of each experiment.

In the pre-study phase, tests for autonomic nerve dysfunction were performed in each patient according to Ewing \& Clarke (1982). The integrity of the cardiovascular parasympathetic system was tested by measuring the heart rate variation during deep breathing and the immediate heart rate response to standing. Sympathetic nerve function was examined by assessing the systolic blood pressure response to standing. A standardized questionnaire was filled out by each patient at three time points, in the pre-study phase $6 \mathrm{~h}$ after breakfast and $6 \mathrm{~h}$ after each ${ }^{13} \mathrm{C}$-octanoic acid breath test. The following subjective gastrointestinal symptoms were scored by the patients from 0 (no symptoms) to 10 (maximal discomfort) for the last $6 \mathrm{~h}$ : loss of appetite, nausea, heartburn, fullness, constipation, diarrhea, abdominal pain, bloating and pain after injection (injection of insulin in the pre-study phase). 


\section{Determination and analysis of ${ }^{13} \mathrm{CO}_{2}$-exhalation data}

Breath samples were taken $15 \mathrm{~min}$ and immediately before meal ingestion, at $15 \mathrm{~min}$ intervals for a period of $240 \mathrm{~min}$, and at $30 \mathrm{~min}$ intervals from 240 to $360 \mathrm{~min}$ after ingestion of the meal. At each sampling point, the patients exhaled into $15 \mathrm{ml}$ vacutainer vials. ${ }^{13} \mathrm{CO}_{2}$ measurements were performed with an isotope ratio mass spectrometer (SIRA 11, VG Isotech, Middlewich, Cheshire, UK) and expressed as the difference of the ${ }^{13} \mathrm{C} /{ }^{12} \mathrm{C}$ ratio $(\mathrm{k}=\%$ ) compared with a reference (Pee Dee Belemnite limestone). Endogenous $\mathrm{CO}_{2}$ production was assumed to be $9 \mathrm{mmol} \mathrm{kg}^{-1}$ body weight $\mathrm{h}^{-1}$. Slopes $(\beta)$ and exhalation velocity constants $(\mathrm{k})$ of the ${ }^{13} \mathrm{CO}_{2}$ exhalation curves were separately calculated for each experiment and each subject using nonlinear least squares regression fitting of the power exponential equation \%dose $/ \mathrm{h}=\mathrm{k} \beta \mathrm{e}^{(-\mathrm{kt})}$ $\left(\left(1-\mathrm{e}^{(-\mathrm{kt})) \mathrm{n}(\beta-1)}\right) \mathrm{m}\right.$, with $\mathrm{m}$ defined as cumulative ${ }^{13} \mathrm{C}$ recovery at infinite time (Ghoos et al. 1993). The results were expressed as percentage of ${ }^{13} \mathrm{CO}_{2}$ in breath per hour corrected for ${ }^{13} \mathrm{C}$ recovery and as cumulative values over $6 \mathrm{~h}$. The lag period of ${ }^{13} \mathrm{CO}_{2}$ exhalation as the time to achieve maximal exhalation velocity was calculated as defined by Siegel et al. $1988(\mathrm{t}(\operatorname{lag})=(\ln \beta) / \mathrm{k})$. The goodness of fit of the fitted nonlinear exhalation curves was assessed as previously described ( ${ }^{2}$; Schirra et al. 1996a).

\section{GLP-1(7-36)amide}

Synthetic GLP-1(7-36)amide was purchased from Saxon Biochemicals (Hannover, Germany). The peptide was delivered as good manufacturing practice-material of pharmaceutical grade with a peptide content of $88.08 \%$ and a peptide purity $>99 \%$. The peptide was dissolved in $1 \% \mathrm{HSA}$, filtered through $0 \cdot 2 \mu \mathrm{m}$ nitrocellulose filters and thereafter stored at $-70{ }^{\circ} \mathrm{C}$. High performance liquid chromatography after sterile filtration confirmed a peptide recovery of $100 \%$ compared with the peptide solution before filtration. Samples were tested for pyrogens and bacterial growth, and no contamination with bacterials or endotoxins was detected. Dose calculations were based on the peptide content of the preparation.

\section{Determinations and assays}

Blood glucose concentrations were measured by the glucose-oxidase method using a glucose analyzer (YSI 1500 G; Schlag, Bergisch-Gladbach, Germany). Plasma immunoreactivities of insulin, C-peptide, glucagon and PP were analyzed by commercially available radioimmunoassay kits (Biermann, Bad Nauheim, Germany and Eurodiagnostica, Malmö, Sweden (PP)). All assays were competitive. For the C-peptide assay, rabbit antihuman C-peptide antibodies, C-peptide standard, and ${ }^{125}$ I-labeled C-peptide tracer were used. Polypropylene tubes coated with antibodies to insulin, human insulin standard and ${ }^{125}$ I-labeled human insulin tracer were used for the insulin assay. Analyses of glucagon were performed using rabbit antihuman glucagon antibodies, human glucagon standard and ${ }^{125}$ I-labeled human glucagon as tracer. For measurement of PP, rabbit antiserum raised against bovine PP, ${ }^{125}$ I-labeled human PP and human PP standard were used.

Immunoreactive (IR) GLP-1 was measured using the specific C-terminal polyclonal antibody GA 1178 (Affinity Research, Nottingham, UK) (Schirra et al. 1996a, 1997). This exhibits $100 \%$ reactivity with GLP-1(1-36)amide, truncated GLP-1(7-36)amide and all further N-terminal truncations. Immunoreactivities were extracted from plasma samples on C-18 cartridges using acetonitrile for elution of samples. This procedure results in $64 \pm 4 \%$ recovery for N-terminally truncated GLP-1 s (Herrmann et al. 1995) when hormone-free plasma was substituted with known amounts of peptides and was then subsequently extracted. The detection limit of the assay was $0 \cdot 25 \mathrm{pmol} / \mathrm{l}$. The antiserum did not crossreact with gastric inhibitory peptide (GIP), pancreatic glucagon, glicentin, oxyntomodulin or GLP-2. Intra- and interassay coefficients of variation were 3.6 and $10 \cdot 2 \%$ respectively.

\section{Statistical analysis}

All values were expressed as means \pm s.E.M. Since changes of blood glucose are associated with changes in IR-insulin, the insulinogenic index was calculated as the quotient IR-insulin/blood glucose, thus more representatively describing insulin release. Differences of plasma hormones, and blood glucose compared with the basal state were calculated as integrated postprandial values over basal (area under the postprandial response curve; AUC). Basal levels of plasma parameters were determined as the mean of the two preprandial values. The time course of ${ }^{13} \mathrm{CO}_{2}$ exhalation in breath was presented as means \pm s.E.M. of individual fitted data. All samples were first tested for normality by the Kolmogoroff-Smirnoff test. Differences between experimental sets for integrated plasma hormone and blood glucose levels were analyzed by two way repeated measures analysis of variance employing test meal and subcutaneous injection as factors. When this analysis indicated that the test meal or the injected substance elicited different responses, a Student-Newman-Keuls multicomparison test was performed. Global ${ }^{13} \mathrm{CO}_{2}$ exhalation parameters were compared by Student's paired $t$-test. Parameters of ${ }^{13} \mathrm{CO}_{2}$ exhalation reflecting gastric emptying, and integrated postprandial immunoreactivities of insulin and glucagon were tested for significant influences on the integrated postprandial blood glucose response using linear regression analysis procedures. Differences were considered significant at $P<0 \cdot 05$.

\section{Results}

Subcutaneous injection of GLP-1 was well tolerated, and none of the patients developed any gastrointestinal 


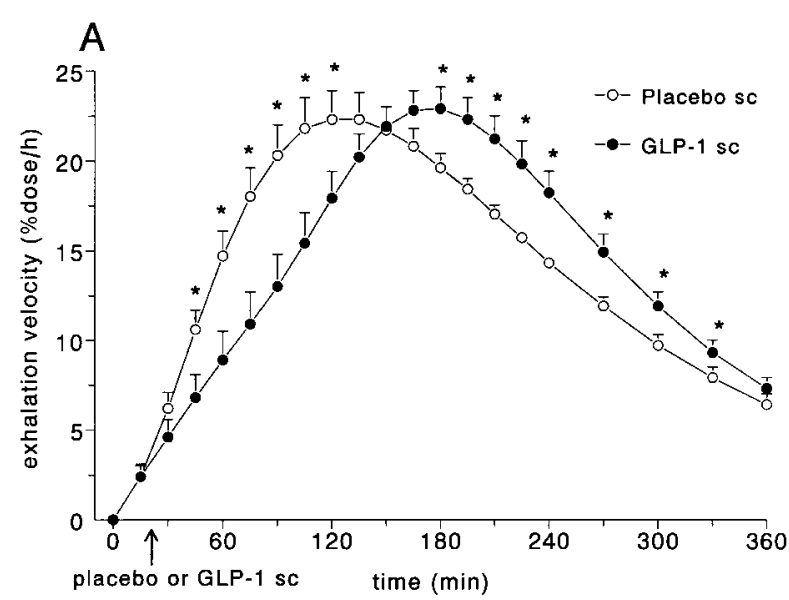

B

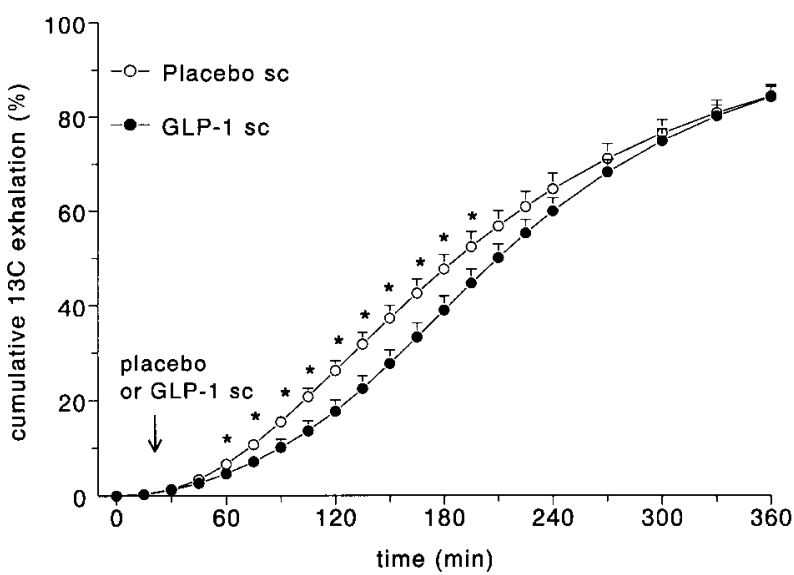

Figure 1 The effects of postprandial subcutaneous injection of placebo or $0.5 \mathrm{nmol} / \mathrm{kg} \mathrm{GLP}-1$ on $(\mathrm{A}){ }^{13} \mathrm{CO}_{2}$ exhalation velocity and (B) cumulative ${ }^{13} \mathrm{CO}_{2}$ exhalation after oral ingestion of a $250 \mathrm{kcal}$ solid meal in 12 patients with NIDDM. Values are means \pm S.E.M. Asterisks denote significant differences $(P<0 \cdot 05)$ between experiments with placebo and GLP-1. For further statistical analysis, see Table 1.

symptoms during the study, neither after placebo nor after GLP-1. However, the patients reported significant pain with the subcutaneous injection of $1 \%$ HSA (mean score $3 \cdot 1 \pm 0 \cdot 6$ ) serving as placebo and 1\% HSA/GLP-1 (2.9 $\pm 0 \cdot 5)$ compared with injection of regular insulin $(0 \cdot 7 \pm 0 \cdot 3, P<0 \cdot 05$ vs $1 \%$ HSA and $1 \%$ HSA/GLP-1). Six of the 12 patients had signs of autonomic neuropathy affecting the parasympathetic cardiovascular system. There were no signs of sympathetic dysfunction in the cardiovascular reflex tests. Comparison of the obese patient group with the lean group did not reveal any significant difference in their response to GLP-1 regarding gastric emptying, or glycemic or endocrine responses.
Table 1 Parameters of ${ }^{13} \mathrm{CO}_{2}$ exhalation of ${ }^{13} \mathrm{C}$-octanoic acid breath test reflecting gastric emptying of an orally ingested $250 \mathrm{kcal}$ mixed meal with and without postprandial subcutaneous injection of GLP-1. ${ }^{13} \mathrm{CO}_{2}$ exhalation parameters were calculated using power exponential fitting according to Ghoos et al. 1993. Values are means \pm S.E.M.. $(n=12)$

\begin{tabular}{|c|c|c|}
\hline & $\begin{array}{l}\text { Placebo } \\
\text { (s.c.) }\end{array}$ & $\begin{array}{l}\text { GLP-1 } \\
(0.5 \mathrm{nmol} / \mathrm{kg})\end{array}$ \\
\hline \multicolumn{3}{|l|}{ Parameter } \\
\hline $\mathrm{k}\left(\mathrm{h}^{-1}\right)$ & $0.52 \pm 0.04$ & $0.56 \pm 0.05$ \\
\hline Slope $\beta$ & $3 \cdot 1 \pm 0 \cdot 2$ & $4 \cdot 7 \pm 0 \cdot 6^{*}$ \\
\hline $\mathrm{m}(\%)$ & $65 \cdot 3 \pm 3 \cdot 8$ & $70 \cdot 6 \pm 5 \cdot 2$ \\
\hline Lag period (min) & $130 \cdot 7 \pm 6 \cdot 6$ & $171 \cdot 2 \pm 9 \cdot 2^{*}$ \\
\hline $50 \%$ exhalation time $(\mathrm{min})$ & $191 \cdot 9 \pm 9 \cdot 8$ & $213 \cdot 1 \pm 10 \cdot 0$ \\
\hline $80 \%$ exhalation time $(\mathrm{min})$ & $323 \cdot 2 \pm 19 \cdot 0$ & $328 \cdot 5 \pm 15 \cdot 3$ \\
\hline
\end{tabular}

$\mathrm{m}$, cumulative ${ }^{13} \mathrm{C}$ recovery at infinite time.

${ }^{*} P<0 \cdot 05$ vs placebo s.c.

\section{Gastric emptying}

Gastric emptying of the solid meal was close to complete in all patients within the $360 \mathrm{~min}$ study period with a cumulative ${ }^{13} \mathrm{CO}_{2}$ exhalation of $84 \cdot 7 \pm 2 \cdot 4 \%$ after placebo and of $84 \cdot 5 \pm 2 \cdot 2 \%$ after GLP-1 respectively. The measured exhalation data fitted well to the power exponential equation with a mean $\mathrm{R}^{2}$ of $0.96 \pm 0.008$ estimating goodness of fit for the nonlinear exhalation curves. Postprandial subcutaneous injection of GLP-1 initially delayed excretion of ${ }^{13} \mathrm{CO}_{2}$ by shifting the shape of the exhalation curve to the right (increase of slope $\beta$ ), but without influence on the exhalation velocity rate $\mathrm{k}$ and the total exhalation time (Fig. 1, Table 1). Compared with placebo, an initial retardation of the ${ }^{13} \mathrm{CO}_{2}$ exhalation velocity from 25 to $100 \mathrm{~min}$ after injection of GLP-1 was followed by a significant acceleration from 160 to $310 \mathrm{~min}$ after injection (Fig. 1A). Correspondingly, the lag period (time to reach maximal emptying velocity) was significantly prolonged. However, the maximal ${ }^{13} \mathrm{CO}_{2}$ exhalation velocity was not affected by GLP-1 (Fig. 1A). Because of the unchanged exponential exhalation rate $\mathrm{k}$, there was no significant effect of GLP-1 on the exhalation half-time and the time to cumulative $80 \%$ exhalation of ${ }^{13} \mathrm{CO}_{2} \cdot{ }^{13} \mathrm{CO}_{2}$ exhalation parameters did not differ between patients with and without signs of autonomic neuropathy of the parasympathetic system.

\section{Plasma hormones and blood glucose}

With placebo, plasma levels of GLP-1 rose from preprandial basal levels of $1 \cdot 0 \pm 0.2 \mathrm{pmol} / 1$ to individual postprandial peak levels of $4 \cdot 4 \pm 0 \cdot 8 \mathrm{pmol} / 1$ within $52 \pm 7 \mathrm{~min}$ after ingestion of the solid meal, and to $8.7 \pm 1.4 \mathrm{pmol} / 1$ within $32 \pm 5 \mathrm{~min}$ after the OGTT respectively (Fig. 2A). The postprandial integrated GLP-1 response after the OGTT approximately doubled the response to the solid meal (Table 2). After subcutaneous injection of $0.5 \mathrm{nmol} / \mathrm{kg}$ GLP-1, plasma levels of GLP-1 promptly rose and 

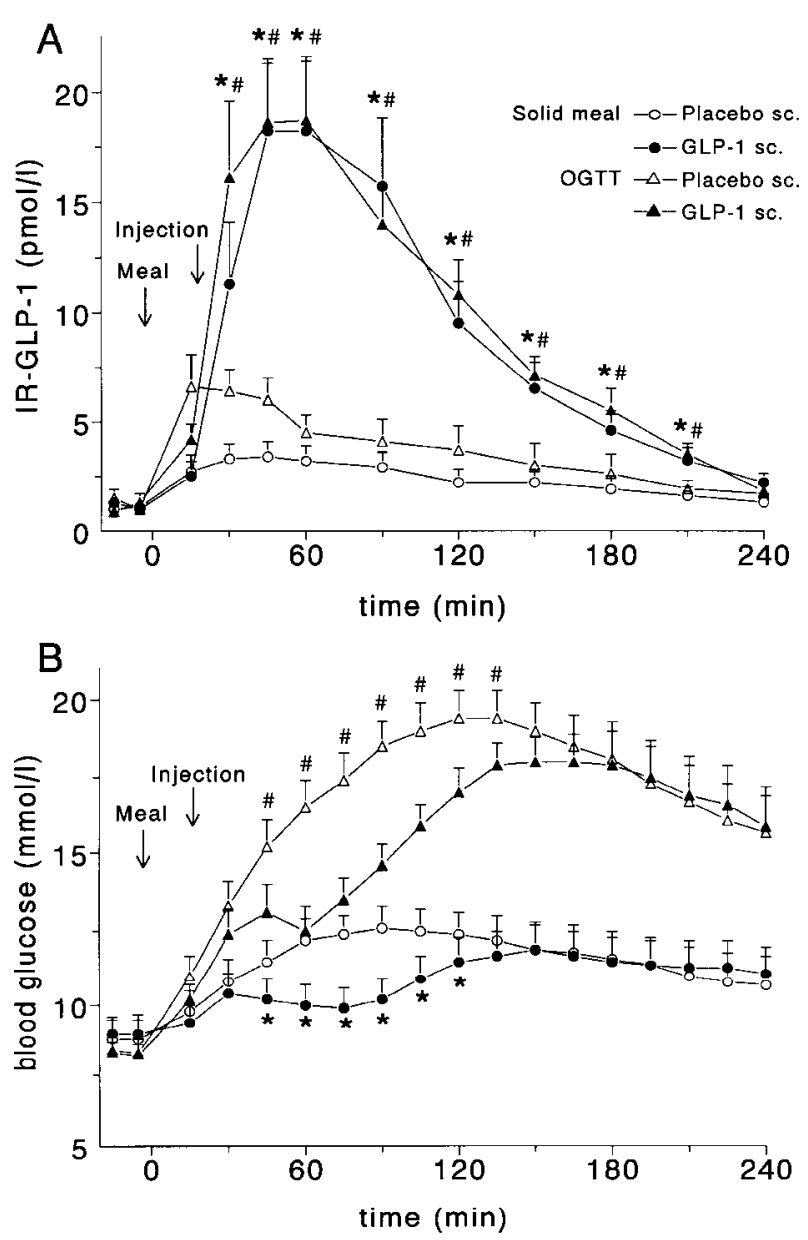

Figure 2 Immunoreactivities of (A) GLP-1 and (B) blood glucose levels after ingestion of a $250 \mathrm{kcal}$ solid meal and an OGTT $(300 \mathrm{kcal})$ in 12 patients with NIDDM in response to postprandial subcutaneous injection of placebo or $0.5 \mathrm{nmol} / \mathrm{kg}$ GLP-1. Values are means \pm S.E.M. Asterisks denote significant differences $(P<0 \cdot 05)$ between experiments with placebo and GLP-1 after ingestion of the solid meal. Hash symbols denote significant differences $(P<0 \cdot 05)$ between experiments with placebo and GLP-1 after ingestion of the OGTT. remained significantly elevated as compared with placebo injection up to $210 \mathrm{~min}$ after meal ingestion being not different between the solid meal and OGTT. Compared with placebo, injection of GLP-1 provided for about 4-fold of the response of GLP-1 to the solid meal, and for about 2 -fold of the response to the OGTT.

Mean preprandial levels of blood glucose of all experiments amounted to $8 \cdot 6 \pm 0.3 \mathrm{mmol} / \mathrm{l}$, and did not differ between study days. With placebo, blood glucose was raised to peak levels of $13.2 \pm 0.7 \mathrm{mmol} / 1$ after the solid meal and to $20 \cdot 3 \pm 0 \cdot 8 \mathrm{mmol} / \mathrm{l}$ after the OGTT (Fig. 2B). Over the total postprandial period of $240 \mathrm{~min}$, integrated blood glucose levels were significantly diminished after both meals with injection of GLP-1 (Table 2). The significant reduction of postprandial glucose levels started $25 \mathrm{~min}$ after peptide injection with both meals. This lasted for $75 \mathrm{~min}$ after intake of the solid meal, and for $90 \mathrm{~min}$ after ingestion of the OGTT. Peak glucose levels were also slightly, but significantly, lower with injection of GLP-1 after both meals $(12.5 \pm 0.7$ vs $13.2 \pm 0.7 \mathrm{mmol} / 1$ after the solid meal, $19 \cdot 3 \pm 0 \cdot 9$ vs $20 \cdot 3 \pm 0 \cdot 8 \mathrm{mmol} / 1$ after the OGTT, $P<0 \cdot 05$ for GLP-1 vs placebo). Thereafter, glucose levels resembled those with placebo, and no rebound of glycemia was observed. During the first $2 \mathrm{~h}$ after meal intake, postprandial incremental glycemia was diminished by $54 \cdot 5 \pm 4 \cdot 4 \%$ after the solid meal, and by $32 \cdot 7 \pm 5 \cdot 5 \%$ after the OGTT $(P<0 \cdot 05)$.

The integrated postprandial responses of IR-insulin (Fig. 3A and B), of IR-C-peptide and, even more pronounced, of the insulinogenic index were significantly elevated with subcutaneous GLP-1 compared with placebo after both meals (Table 2). With the solid meal, plasma levels of insulin were significantly raised $25 \mathrm{~min}$ after injection of GLP-1, and the elevation lasted for 105 min. With ingestion of the OGTT, IR-insulin increased $10 \mathrm{~min}$ after GLP-1 injection and remained significantly elevated for $150 \mathrm{~min}$. Compared with placebo, GLP-1 enhanced the integrated incremental insulin response by $64 \cdot 4 \pm 10 \cdot 0 \%$ (solid meal) and $63 \cdot 3 \pm 14 \cdot 5 \%$ (OGTT) (Table 2).

Table 2 Effect of postprandial subcutaneous injection of GLP-1 on integrated postprandial response curves (AUC) over basal for blood glucose and immunoreactivities (IR) of plasma hormones after oral ingestion of a mixed solid meal (250 kcal) and an OGTT (300 kcal) in NIDDM. Values are means \pm S.E.M.. $(n=12)$

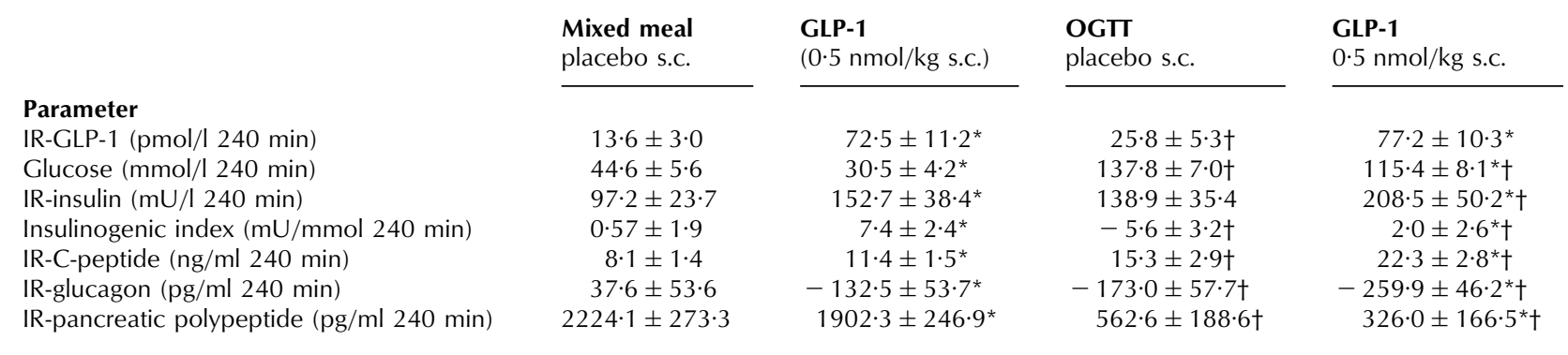



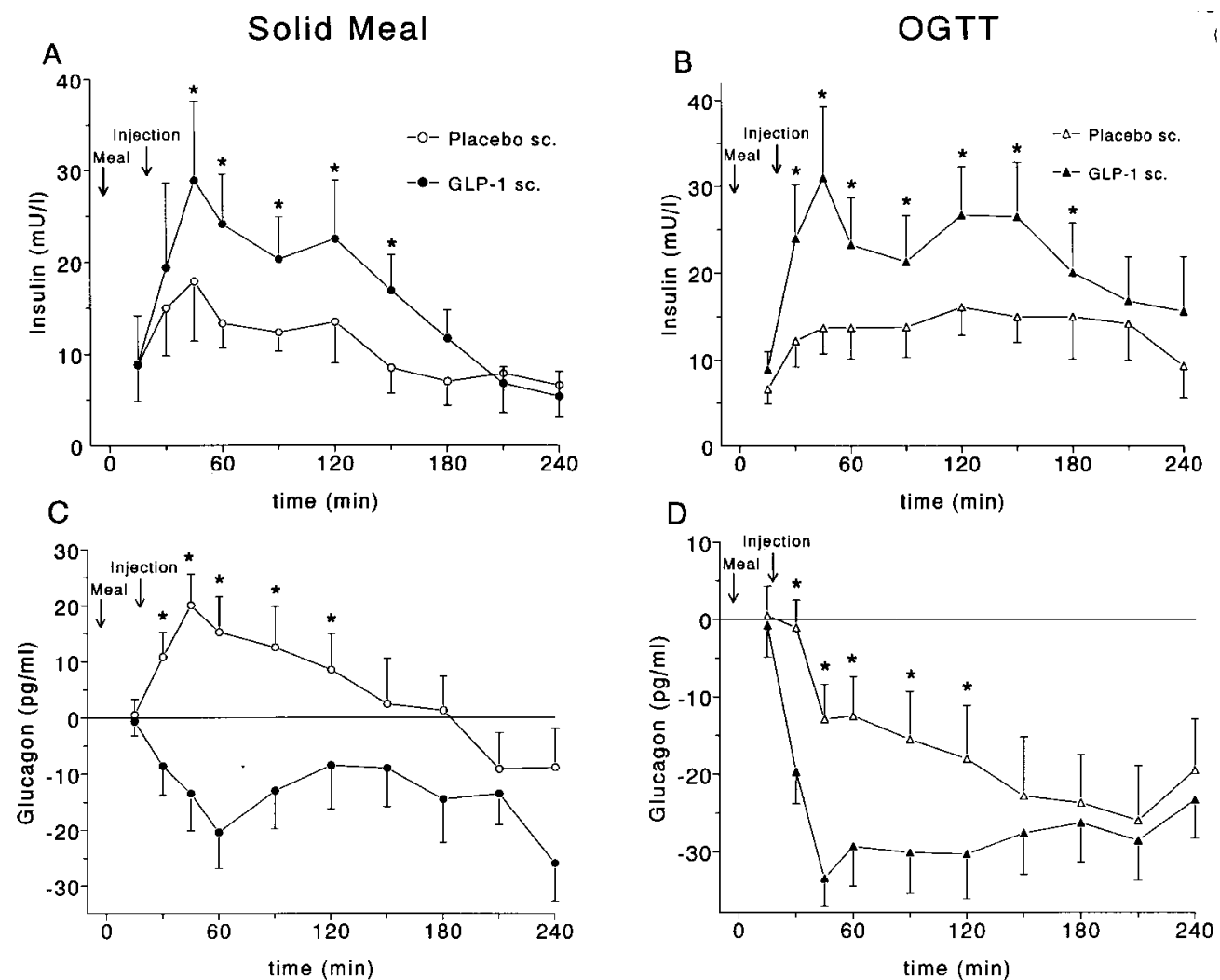

Figure 3 Immunoreactivities of insulin ( $A$ and $B$ ) and glucagon $(C$ and $D)$ over basal, i.e., mean of values at -10 and $0 \mathrm{~min}$, after ingestion of a $250 \mathrm{kcal}$ solid meal (A and $C$ ) and a $300 \mathrm{kcal}$ OGTT (B and D) in 12 patients with NIDDM in response to postprandial subcutaneous injection of placebo or $0.5 \mathrm{nmol} / \mathrm{kg} \mathrm{GLP}-1$. Values are means \pm S.E.M. Asterisks denote significant differences $(P<0 \cdot 05)$ between experiments with placebo and GLP-1.

IR-glucagon increased after the solid meal, whereas the OGTT inhibited the release of IR-glucagon (Fig. 3C and D). With GLP-1, postprandial IR-glucagon was reduced after both meals (Fig. 3C and D, Table 2). In contrast to the experiments with placebo, nine of 12 patients showed a decrease of IR-glucagon in response to the solid meal instead of an increase. With both meals and compared with placebo, the reduction of IR-glucagon started $10 \mathrm{~min}$ after injection of GLP-1 and the reduction remained significant over a period of $90 \mathrm{~min}$. Thereafter, IRglucagon in plasma with and without GLP-1 was not different.

To test IR-insulin, IR-glucagon, and gastric emptying as determinants of the reduction in glycemia from 45 to $120 \mathrm{~min}$ (Fig. 2B), linear regression procedures were performed. The reduction of glycemia after GLP-1 injection showed a significant inverse correlation with the prolongation of the lag period of ${ }^{13} \mathrm{CO}_{2}$ exhalation $(r=0.62, P=0.033)$, a high correlation with inhibition of IR-glucagon $(r=0 \cdot 83, P=0 \cdot 0008)$, a significant inverse correlation with stimulation of IR-C-peptide of inter- mediate strength $(r=0.62, P=0.032)$ and no correlation with changes of IR-insulin $(r=0 \cdot 39, P=0 \cdot 217)$. Stepwise and multiple linear regression analyses revealed a significantly better correlation for these parameters combined $(r=0.969, P<0.0001)$, with changes of IR-insulin $(P=$ 0.0012), IR-glucagon $(P=0.0019)$ and the duration of the lag period $(P=0.0012)$, independently associated with the postprandial reduction of blood glucose.

After ingestion of the solid meal, there was a marked increase of IR-PP, whereas after the OGTT, a mild increase of IR-PP was observed. Subcutaneous GLP-1 reduced IR-PP after both meals (Fig. 4A and B, Table 2). After an initial increase with meal ingestion, IR-PP decreased immediately after subcutaneous injection of GLP-1 with a nadir 40 min after injection followed by a rapid recovery. After the solid meal, the IR-PP peak was significantly reduced and postponed with GLP-1 injection. Here, the inhibition was maintained for $45 \mathrm{~min}$, and from 120 min after meal ingestion onwards, plasma levels of IR-PP were not significantly different with and without GLP-1. 

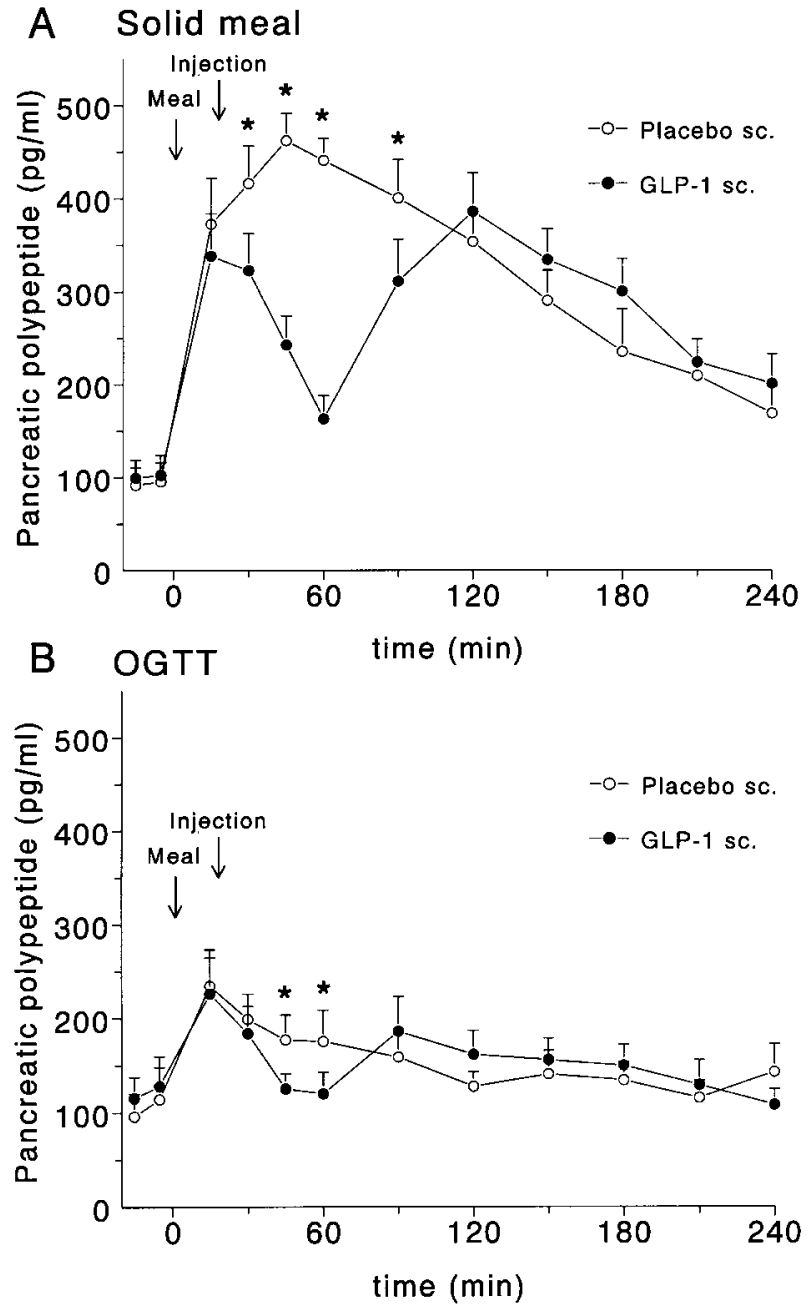

Figure 4 Immunoreactivities of pancreatic polypeptide after ingestion of (A) a $250 \mathrm{kcal}$ solid meal and (B) a $300 \mathrm{kcal}$ OGTT in 12 patients with NIDDM in response to postprandial subcutaneous injection of placebo or $0.5 \mathrm{nmol} / \mathrm{kg}$ GLP-1. Values are means \pm S.E.M. Asterisks denote significant differences $(P<0 \cdot 05)$ between experiments with placebo and GLP-1.

\section{Discussion}

Several novel findings of this study in patients with NIDDM are reported. Subcutaneous injection of GLP-1 $(0.5 \mathrm{nmol} / \mathrm{kg}$ given early postprandially) prolonged the lag period of gastric emptying of a solid meal, i.e. the time to maximal emptying velocity. The overall ${ }^{13} \mathrm{CO}_{2}$ exhalation rate $\mathrm{k}$, the ${ }^{13} \mathrm{CO}_{2}$ exhalation half-time and the time to cumulative $80 \%$ exhalation of ${ }^{13} \mathrm{CO}_{2}$ remained unaffected. After ingestion of the solid meal or of the OGTT, GLP-1 retarded the postprandial elevation of blood glucose, diminished the postprandial glucose peak and reduced the total glucose response. GLP-1 also enhanced the postprandial release of insulin. GLP-1 completely abolished the postprandial increase of plasma glucagon after the solid meal, and further augmented the inhibition of glucagon after the OGTT. Postprandial release of PP as a humoral marker of cholinergic tone was inhibited by GLP-1 injection. The initial delay of gastric emptying, the enhancement of postprandial insulin release and the inhibition of postprandial glucagon release were independent determinants of the postprandial glucose response in NIDDM after subcutaneously and postprandially injected GLP-1.

Parenteral application of GLP-1 is mandatory to circumvent enteral degradation of orally ingested peptide. Preprandial subcutaneous injection (Gutniak et al. 1994, Schirra et al. 1997) or a buccal tablet (Gutniak et al. 1996) of GLP-1 resulted in fast absorption with a rapid increase of GLP-1 immunoreactivity in plasma. The rapid metabolism of GLP-1, however, limits the duration of its action (Gutniak et al. 1996). Increasing the subcutaneous dose of the peptide also does not overcome the problem of rapid metabolic clearance, because the development of side effects like nausea and vomiting is related to the peak plasma levels of GLP-1 (Ritzel et al. 1995, J Schirra, P Leicht \& $\mathrm{M}$ Katschinski, unpublished observations). On the other hand, gastric emptying of nutrient meals exhibits an exponential pattern implying that the postprandial delivery of nutrients into the duodenum is near maximal within the first $30 \mathrm{~min}$ (Schirra et al. 1996a, 1997). In order to exploit the fast peptide absorption from subcutaneous tissue and to optimize the endocrine effects of GLP-1, we utilized an alternative time approach by simply injecting GLP-1 20 min after meal ingestion when the velocity of gastric emptying is near maximal and the postprandial glycemia develops.

Plasma immunoreactivities of GLP-1 showed a prompt and steep rise after peptide injection reflecting a rapid absorption from the subcutaneous tissue followed by a fast decline. Compared with endogenous GLP-1 release by a meal, postprandial subcutaneous injection of GLP-1 mimicked the time course of GLP-1 immunoreactivity in plasma, but at a supraphysiological level.

The C-terminally directed GLP-1 antiserum used in the present study measured the immunoreactivity of N-terminally truncated GLP-1 including biologically active GLP-1(7-36)amide and the inactive metabolite GLP1(9-36)amide. However, as it is known from studies with application of exogenous GLP-1(7-36)amide (Deacon et al. 1995b, Gutniak et al. 1996), bioactive GLP-1(736)amide parallels the time course of total truncated GLP-1 immunoreactivity, but the elevation lasts for a shorter period. Therefore, in previous studies (Gutniak et al. 1994, Nauck et al. 1996) and in the present work with subcutaneous GLP-1, the use of a C-terminally directed antiserum would lead to an overestimation of the absolute concentrations and the duration of elevation of bioactive GLP-1(7-36)amide, which would account for the shorter duration of the observed endocrine effects compared with the elevation of GLP-1 immunoreactivity in plasma. 
The ${ }^{13} \mathrm{C}$-labeled octanoic acid breath test has been validated as a non-invasive test for gastric emptying of a solid meal (Ghoos et al. 1993). Moreover, this test was shown to sensitively register pharmacological modulations of gastric emptying rates of solids (Maes et al. 1994). In keeping with previous studies with direct measurement of gastric emptying (Schirra et al. 1996a, 1997), ${ }^{13} \mathrm{CO}_{2}$ exhalation exhibited a nonlinear pattern with an initial lag period $(\beta>1)$ as the time to reach maximal exhalation velocity comparable to the lag period of gastric emptying. Subcutaneous GLP-1 delayed the initial phase of ${ }^{13} \mathrm{CO}_{2}$ exhalation with a significant increase of the slope $\beta$ of the exhalation curve. This resulted in a prolongation of the lag period. Nevertheless, after this initial inhibition, ${ }^{13} \mathrm{CO}_{2}$ exhalation velocity was temporarily faster, reflecting acceleration of gastric emptying after GLP-1. The exponential exhalation rate $\mathrm{k}$ was unaffected, and there was no effect on the cumulative ${ }^{13} \mathrm{CO}_{2}$ exhalation at the half-time and thereafter. The kinetics of gastric emptying mirrors the effects of subcutaneous injection of GLP-1 on gastric emptying of a mixed liquid meal in healthy subjects measured by a direct method (Schirra et al. 1997). In contrast to recently published studies in patients with NIDDM suggesting intravenous (Willms et al. 1996) or preprandially subcutaneously injected GLP-1 (Nauck et al. 1996) to cause a near complete inhibition of gastric emptying of liquid meals, a complete inhibition after subcutaneous GLP-1 did not occur in our study. The single marker dilution technique for measurement of gastric emptying used in these studies allows assessment of intragastric volumes but not of gastric emptying because this method does not account for the gastric secretory activity after ingestion of hyperosmolar liquids (Schirra et al. 1996a). Thus, it underestimates the gastric emptying rate. In the present and our previous study (Schirra et al. 1997) we showed that gastric emptying occurs at each postprandial time point with solid and with liquid meals, and even GLP-1 plasma immunoreactivities amounting to about 3- to 5-fold increases of postprandial plasma levels with placebo were not able to fully inhibit gastric emptying.

Motor mechanisms controlling gastric emptying are antral contractility, antro-duodenal wave propagation, the pyloric tone, isolated pyloric pressure waves and the tone of the gastric fundus (Camilleri et al. 1985, Houghton et al. 1988, Tougas et al. 1992, Heddle et al. 1993). In humans, step-doses of intravenous GLP-1 were shown to inhibit isolated pyloric pressure waves and to elevate basal pyloric tone with intraduodenal lipid perfusion in a dosedependent manner, and a complete abolition of antropyloro-duodenal wave propagation in the interdigestive state was observed (Schirra et al. 1996b). Moreover, inhibition of gastric emptying of a liquid meal after subcutaneous GLP-1 injection was associated with dosedependent inhibition of antral contractile activity and of coordinated antro-duodenal contractions (Schirra et al.
1997). The accelerated gastric emptying with subcutaneous GLP-1 in the post-lag period has been recently shown to be associated with an increase of coordinated antroduodenal motor events in healthy subjects (Schirra et al. 1997).

The inhibition of PP, a hormone of the endocrine pancreas under strong vagal cholinergic control, was also found in healthy subjects immediately after subcutaneous injection of GLP-1 (Schirra et al. 1997). Intestinal stimulation of PP release requires stimulation of enteropancreatic cholinergic reflexes by duodenal delivery of nutrients (Schwartz 1983). However, since GLP-1 did not alter the total amount of nutrients emptied from the stomach but significantly diminished PP release, the effects on PP are primarily independent of gastric emptying. Therefore, we suggest that GLP-1 inhibits efferent vagal-cholinergic activity, thereby diminishing PP release and at least contributing to delayed gastric emptying via a central pathway. This concept is compatible with GLP-1 inhibiting gastric acid secretion in response to sham feeding (Wettergren et al. 1994). Receptors for GLP-1 are present in circumventricular organs like the subfornical organ, the nucleus of the solitary tract and the area postrema (Göke et al. 1995). In addition, it has been recently shown in the rat that GLP-1 induced inhibition of gastric emptying involves a capsaicin-sensitive pathway indicating a stimulation of vagal afferent nerves by GLP-1 (Imeryuz et al. 1997). A direct action of GLP-1 on pancreatic PP cells or a paracrine effect via somatostatin which could mediate this effect seem unlikely, because GLP-1 induces a stimulation instead of an inhibition of PP release from isolated human pancreatic islets (Fehmann et al. 1995b).

Postprandially injected subcutaneous GLP-1 reduced the postprandial glucose elevations during the first two postprandial hours by about $55 \%$ (solid meal) and by about $33 \%$ (OGTT). It enhanced total insulin release, completely abolished the release of glucagon with the solid meal and further inhibited glucagon secretion after ingestion of the OGTT. These results are in accordance with the endocrine response to intravenous infusion of GLP-1 (Kreymann et al. 1987, Gutniak et al. 1992, Nathan et al. 1992, Nauck et al. 1993), and with the effects of a preprandial subcutaneous injection of GLP-1 in healthy subjects (Schirra et al. 1997) or in diabetic patients (Gutniak et al. 1994). In the study of Gutniak et al. (1994) in patients with NIDDM, the magnitude of reduction in glycemia was rather weak after preprandial subcutaneous injection of GLP-1 compared with placebo injection. In a recent study in NIDDM, a reduction of postprandial glycemia, comparable to our results, was observed with GLP-1 injected 30 min before ingestion of a liquid meal (Nauck et al. 1996). However, the dose of GLP-1 used in their study amounted to threefold our dose. The insulinotropic effect of preprandially administered GLP-1 depended on the marked preprandial hyperglycemia (about $11 \mathrm{mmol} / \mathrm{l})$ and occurred before meal ingestion whereas 
during the postprandial phase insulin plasma levels did not differ from placebo. Moreover, the postprandial plasma levels of glucagon increased with only a short initial reduction after GLP-1 injection instead of a decrease as shown in the present study. These endocrine effects argue in favor of subcutaneously administering GLP-1 in the early postprandial period.

Primarily independent determinants of the postprandially lowered glucose with GLP-1 were the stimulation of insulin release, the reduction of glucagon secretion, and the initial delay of gastric emptying, with all of these mechanisms coming into effect immediately after GLP-1 injection. The insulinotropic action of GLP-1 is mediated by specific GLP-1 receptors on the B-cell, and the inhibition of glucagon release from the A-cell is thought to be mediated by a glucose-independent paracrine action of pancreatic somatostatin stimulated by GLP-1 (Fehmann et al. 1995). The fast rise of plasma insulin after GLP-1, despite the delay of gastric emptying, may have been caused by the preexisting hyperglycemia, whereas the rapid decline of plasma glucagon may have been further supported by the retardation of nutrient delivery into the small intestine. An additional, although so far rather speculative, effect of subcutaneous GLP-1 on insulinindependent glucose utilization in peripheral tissues (D'Alessio et al. 1994, 1995) may also contribute to the lowered postprandial glucose response, whereas GLP-1 does not seem to improve insulin resistance in NIDDM (Ahrén et al. 1997).

Inhibition of gastric emptying is not the predominant determinant of the postprandial glucose response after subcutaneous GLP-1. The ongoing stimulation of insulin and inhibition of glucagon release even in the post-lag phase of gastric emptying are suggested to prevent a rise in blood glucose, which would otherwise be induced by the even higher emptying velocity of nutrients with GLP-1. Due to the fast absorption from the subcutaneous tissue, injection in the early postprandial phase improves the efficacy of subcutaneously applied GLP-1 in NIDDM, since high GLP-1 levels are optimal when gastric emptying is near maximal. Postprandial application of an antidiabetic agent would simplify the therapy of NIDDM, and GLP-1, either by subcutaneous injection or as a buccal tablet (Gutniak et al. 1996), offers this opportunity.

\section{Acknowledgements}

This work was supported by grants from the Deutsche Forschungsgemeinschaft (Ar 149/1-1 and Ar 149/1-2). The excellent technical assistance of Gabriele Kraft and Michaela Junck is gratefully appreciated. We thank Elisabeth Bothe for precise measurements of pancreatic polypeptide and Mrs Maiszies for the sterile preparation of GLP-1.

\section{References}

Ahrén B, Larsson H \& Holst JJ 1997 Effects of glucagon-like peptide-1 on islet function and insulin sensitivity in noninsulin-dependent diabetes mellitus. Journal of Clinical Endocrinology and Metabolism 82 473-478.

Camilleri M, Malagelada JR, Brown ML, Becker G \& Zinsmeister AR 1985 Relation between antral motility and gastric emptying of solids and liquids in humans. American Journal of Physiology 249 G580-G585.

D’Alessio DA, Kahn SE, Leusner CR \& Ensinck JW 1994 Glucagon-like peptide 1 enhances glucose tolerance both by stimulation of insulin release and by increasing insulin-independent glucose disposal. Journal of Clinical Investigation 93 2263-2266.

D’Alessio DA, Brigeon RL \& Ensinck JW 1995 Enteral enhancement of glucose disposition by both insulin-dependent and insulinindependent processes. A physiological role of glucagon-like peptide 1. Diabetes 44 1433-1437.

Deacon CF, Johnsen AH \& Holst JJ 1995a Degradation of glucagon-like peptide-1 by human plasma in vitro yields an $\mathrm{N}$-terminally truncated peptide that is a major endogenous metabolite in vivo. Journal of Clinical Endocrinology and Metabolism 80 952-957.

Deacon CF, Nauck MA, Toft-Nielsen M, Pridal L, Willms B \& Holst JJ 1995 both subcutaneously and intravenously administered glucagon-like peptide I are rapidly degraded from the $\mathrm{NH}_{2}-$ terminus in type II diabetic patients and in healthy subjects. Diabetes 44 1126-1131.

Ewing DJ \& Clarke BF 1982 Diagnosis and management of diabetic autonomic neuropathy. British Medical Journal 285 916-918.

Fehmann HC, Göke R \& Göke B 1992 Glucagon-like peptide-1(7-37)/(7-36)amide is a new incretin. Molecular and Cellular Endocrinology 85 C39-C44.

Fehmann HC, Göke R \& Göke B 1995a Cell and molecular biology of the incretin hormones glucagon-like peptide-1 and glucosedependent insulin releasing polypeptide. Endocrine Reviews 16 390-410.

Fehmann HC, Hering BJ, Wolf MJ, Brandhorst H, Brandhorst D, Bretzel RG, Federlin K \& Göke B $1995 b$ The effects of glucagon-like peptide-1 (GLP-1) on hormone secretion from isolated human pancreatic islets. Pancreas 11 196-200.

Ghoos YF, Maes BD, Geypens BJ, Mys G, Hiele MI, Rutgeerts PJ \& Vantrappen G 1993 Measurement of gastric emptying rate of solids by means of a carbon-labeled octanoic acid breath test. Gastroenterology 104 1640-1647.

Göke R, Fehmann HC \& Göke B 1991 Glucagon-like peptide-1(7-36)amide is a new incretin/enterogastrone candidate. European Journal of Clinical Investigation 21 135-144.

Göke R, Larsen PJ, Mikkelsen JD \& Sheikh SP 1995 Distribution of GLP-1 binding sites in the rat brain: evidence that exendin-4 is a ligand of brain GLP-1 binding sites. European Journal of Neuroscience 7 2294-2300.

Gutniak MK, Ørskov C, Holst JJ, Ahrén B \& Efendic S 1992 Antidiabetogenic effect of glucagon-like peptide 1 (7-36) in normal subjects and patients with diabetes mellitus. New England Journal of Medicine 326 1316-1322.

Gutniak MK, Linde B, Holst JJ \& Efendic S 1994 Subcutaneous injection of the incretin hormone glucagon-like peptide 1 abolishes postprandial glycemia in NIDDM. Diabetes Care 17 1039-1044.

Gutniak MK, Larsson H, Heiber SJ, Juneskans OT, Holst JJ \& Ahrén B 1996 Potential therapeutic levels of glucagon-like peptide 1 achieved in humans by a buccal tablet. Diabetes Care 19 843-848.

Heddle R, Miedema BW \& Kelly KA 1993 Integration of canine proximal gastric, antral, pyloric, and proximal duodenal motility during fasting and after a liquid meal. Digestive Diseases and Sciences 38 856-869.

Herrmann C, Göke R, Richter G, Fehmann HC, Arnold R, and Göke B 1995 Glucagon-like peptide-1 and glucose-dependent 
insulin-releasing polypeptide plasma levels in response to nutrients. Digestion 56 117-126.

Houghton LA, Read NW, Heddle R, Horowitz M, Collins PJ, Chatterton B \& Dent J 1988 Relationship of the motor activity of the antrum, pylorus, and duodenum to gastric emptying of a solid-liquid mixed meal. Gastroenterology 94 1285-1291.

Imeryuz N, Bozkurt A, Alican I \& Ulusoy NB 1997 The role of GLP-1 in glucose-induced inhibition of gastric emptying in conscious rats. Gastroenterology 112 A753.

Kolligs F, Fehmann HC, Göke R \& Göke B 1995 Reduction of the incretin effect in rats by the glucagon-like peptide 1 receptor antagonist exendin(9-39)amide. Diabetes 44 16-19.

Kreymann B, Ghatei MA, Williams G \& Bloom SR 1987 Glucagon-like peptide-1-(7-36): a physiological incretin in man. Lancet 2 1300-1305.

Maes BD, Hiele MI, Geypens BJ, Rutgeerts PJ, Ghoos YF \& Vantrappen G 1994 Pharmacological modulation of gastric emptying rate of solids as measured by the carbon labeled octanoic acid breath test: influence of erythromycin and propantheline. Gut 35 333-337.

Nathan DM, Schreiber E, Fogel H, Mojsov S \& Habener JF 1992 Insulinotropic action of glucagonlike peptide-1-(7-37) in diabetic and nondiabetic subjects. Diabetes Care 15 270-276.

Nauck MA, Heimesaat MM, Ørskov C, Holst JJ, Ebert R \& Creutzfeldt W 1993 Preserved incretin activity of glucagon-like peptide 1 (7-36 amide) but not of synthetic human gastric inhibitory polypeptide in patients with type-2 diabetes mellitus. Journal of Clinical Investigation 91 301-307.

Nauck MA, Wollschläger D, Werner J, Holst JJ, Ørskov C, Creutzfeldt W \& Willms B 1996 Effects of subcutaneous glucagon-like peptide 1 (GLP-1 (7-36 amide)) in patients with NIDDM. Diabetologia 39 1546-1553.

Rachman J, Gribble FM, Barrow BA, Levy JC, Buchanan KD \& Turner RC 1996 Normalization of insulin responses to glucose by overnight infusion of glucagon-like peptide 1(7-36)amide in patients with NIDDM. Diabetes 45 1524-1530.

Ritzel R, Ørskov C, Holst JJ \& Nauck MA 1995 Pharmacokinetic, insulinotropic, and glucagonostatic properties of GLP-1(7-36)amide after subcutaneous injection in healthy volunteers. Dose-responserelationships. Diabetologia 38 720-725.

Robertson DA, Hale PJ \& Nattrass M 1988 Macrovascular disease and hyperinsulinemia. In Baillière's Clinical Endocrinology and Metabolism, pp 407-424. Eds M Nattrass \& PJ Hale. London: Baillière Tindall.

Schirra J, Katschinski M, Weidmann C, Schäfer T, Wank U, Arnold R \& Göke B 1996a Gastric emptying and release of incretin hormones after glucose ingestion in humans. Journal of Clinical Investigation 97 92-103.
Schirra J, Wank U, Houck P, Göke B \& Katschinski M $1996 b$ Effects of GLP-1 on human antro-pyloro-duodenal motility. Gastroenterology 110 A1116.

Schirra J, Kuwert P, Wank U, Leicht P, Arnold R, Göke B \& Katschinski M 1997 Differential effects of subcutaneous GLP-1 on gastric emptying, antro-duodenal motility, and pancreatic function in man. Proceedings of the Association of American Physicians 109 84-97.

Schwartz TW 1983 Pancreatic polypeptide: a hormone under vagal control. Gastroenterology 85 1411-1425.

Siegel JA, Urbain JL, Adler LP, Charkes ND, Maurer AH, Krevsky B, Knight LC, Fisher RS \& Malmud LS 1988 Biphasic nature of gastric emptying. Gut 29 85-89.

Thorens B, Porret A, Bühler L, Deng SP, Morel P \& Widmann C 1993 Cloning and functional expression of the human islet GLP-1 receptor. Demonstration that exendin-4 is an agonist and exendin-(9-39) an antagonist of the receptor. Diabetes $\mathbf{4 2}$ $1678-1682$.

Tougas G, Anvari M, Richards D, Dent J, Somers S \& Stevenson GW 1992 Relation of pyloric motility to pyloric opening and closure in healthy subjects. Gut 33 466-471.

Wang Z, Wang RM, Owji AA, Smith DM, Ghatei MA \& Bloom SR 1995 Glucagon-like peptide-1 is a physiological incretin in rat. Journal of Clinical Investigation 95 417-421.

Weir GC, Mojsov S, Hendrick GK \& Habener JF 1989 Glucagon-like peptide 1 (7-37) actions on endocrine pancreas. Diabetes $\mathbf{3 8}$ 338-342.

Wettergren A, Schjoldager B, Mortensen PE, Myhre J, Christiansen J \& Holst JJ 1993 Truncated GLP-1 (proglucagon 78-107-amide) inhibits gastric and pancreatic functions in man. Digestive Diseases and Sciences 4 665-673.

Wettergren A, Petersen H, Ørskov C, Christiansen J, Sheikh SP \& Holst JJ 1994 Glucagon-like peptide-1-(7-36)amide and peptide YY from the L-cell of the ileal mucosa are potent inhibitors of vagally induced gastric acid secretion in man. Scandinavian Journal of Gastroenterology 29 501-505.

Willms B, Werner J, Holst JJ, Ørskov C, Creutzfeldt W \& Nauck MA 1996 Gastric emptying, glucose responses, and insulin secretion after a liquid test meal: effects of exogenous glucagon-like peptide-1 (GLP-1)-(7-36)amide in type 2 (non-insulin-dependent) diabetic patients. Journal of Clinical Endocrinology and Metabolism 81 327332.

Received 12 May 1997

Accepted 26 August 1997 